\title{
La crisis epidemiológica global en el marco de la crisis epocal del capitalismo
}

\author{
The global epidemiological crisis \\ in the framework of epochal crisis of capitalism
}

Luis Arizmendi*

ISSN IMPRESO 1870-7599 | ISSN RED CÓMPUTO 2448-7783 | 7-32

RECIBIDO 08/03/20 | ACEPTADO 23/03/20

\begin{abstract}
Resumen. La crisis epidemiológica del capitalismo del siglo XXI incluye pero desborda la pandemia por covid-19, puesto que es la quinta de las epidemias de este tipo que comenzaron hace casi dos décadas. Como segundo eje de la crisis ambiental mundializada, al lado del sobrecalentamiento planetario, constituye una dimensión esencial de la crisis epocal del capitalismo. El coronavirus no es producto de una bioarma, sino resultado de la alteración antiecológica radical que la economía alimentaria capitalista le impone a la naturaleza por su subordinación a enormes poderes corporativos globales. La tendencia a estado de excepción planetario ha sido la respuesta predominante del capitalismo ante la pandemia. Desde ella, los migrantes, en el Norte global, han sido colocados tanto en las filas de una fuerza laboral imprescindible como de una masa social cercenable. La crisis por covid-19 ha puesto al descubierto que el capitalismo, cada vez más violento, está dispuesto a manejar neoautoritariamente todas las dimensiones de su crisis epocal. De asumir a contrapelo los límites a que ha arribado su señorío sobre la naturaleza planetaria, dependerá la gestación de una urgente modernidad alternativa y que el futuro pueda comenzar hoy.
\end{abstract}

Palabras clave: crisis epocal, crisis epidemiológica, estado de excepción, capitalismo de la vigilancia, tendencia neoautoritaria, migración forzada internacional.

\begin{abstract}
The epidemiological crisis of 21st Century capitalism includes but goes beyond the covid-19 pandemic, as this is the fifth epidemic of its kind to have occurred in the past two decades. A second axis of the world environmental crisis, alongside global warming, it represents an essential dimension of the epochal crisis of capitalism. The coronavirus is not a bioweapon, but rather the outcome of a radical anti-ecological disruption that the capitalist food economy imposed on nature through its subordination to massive global corporate powers. The tendency toward a planetary state of emergency has been the primary response of capitalism in the face of the pandemic. As such, migrants in the Global North find themselves among the ranks of the essential labor force as a (cercenable) social group. The covid-19 crisis has exposed the reality that capitalism is driven to confront all of the dimensions of its epochal crisis in an ever-more violent neo-authoritative manner. Countering the extent of its dominion over the global environment will require the creation of an urgently needed alternative modernity, one that can lead us into the future beginning today.
\end{abstract}

Keywords: epochal crisis, epidemiological crisis, state of emergency, surveillance capitalism, neo-authoritarian tendency, international forced migration.

\footnotetext{
* Mexicano. Docente de la Escuela Superior de Economía del Instituto Politécnico Nacional y director de la revista Mundo Siglo XXI de la misma institución. Correo-e: arizmendi_luis@hotmail.com
} 


\section{Crisis epidemiológica global y crisis epocal del capitalismo}

Crisis epidemiológica del capitalismo del siglo XXI constituye una expresión crítica e histórica ad hoc para dar cuenta de una situación límite mayor que incluye pero desborda, a la vez, la actual epidemia mundializada por el coronavirus. Si se mira retrospectivamente, emerge que covid-19 es la quinta de una serie de epidemias que comenzaron con el nuevo siglo: el SARS en 2002, la gripe aviar en 2005, la gripe porcina en 2009 - la crisis de la influenza que comenzó en México, en las Granjas Carroll en Veracruz-, y el síndrome respiratorio de Oriente Medio (MERS-Cov) en 2012, constituyeron los implacables anuncios previos de que había surgido una nueva dimensión esencial de la crisis epocal del capitalismo. De manera prospectiva, puede verse entonces que, aunque una vacuna para enfrentar la covid-19 se empiece a generalizar, quizá a partir de mediados de 2021, si no es que después, e incluso si logra ser eficaz para tratar médicamente la amplia cantidad de mutaciones sucedidas en el coronavirus, de ningún modo eso significará la superación histórica de la crisis epidemiológica del capitalismo. Lo anterior puesto que aún no concluye esta pandemia y el proceso de generación de un nuevo virus detonante de otra epidemia mundializable, perfectamente, podría estar ya en curso.

Si se lee desde el horizonte propio de la crítica al capitalismo en clave de valor de uso o, lo que es lo mismo, desde la vida humana como fundamento, debería afirmarse que, agudizando los impactos de la crisis de sobreacumulación planetaria y la crisis de la hegemonía americana, más aún de la mundialización de la pobreza, la crisis alimentaria global y la crisis de la migración forzada internacional, la actual pandemia por covid-19 se ha expandido vertiginosamente por el orbe, como ninguna otra epidemia previa en la historia moderna, volviendo inocultable que, al lado del sobrecalentamiento planetario, ella constituye el segundo eje de la crisis ambiental mundializada, y va a seguir impactando en el nuevo siglo en tanto con el capitalismo persista su alteración antiecológica radical, impuesta desde la economía alimentaria global contra la naturaleza.

En efecto, no es la naturaleza la que se encuentra en guerra con la humanidad, más bien, al revés, para decirlo empleando una formulación inventada por Naomi Klein, es el capitalismo el que se encuentra en guerra con la naturaleza. A contrapelo del discurso del poder que propulsa la tendencia hacia un 
estado de excepción planetario y su concomitante violencia político-destructiva, es imprescindible decir que de ningún modo la crisis epidemiológica agudizada por la covid-19 es resultado de un «enemigo invisible» que se ha propagado por el orbe. Asumir la naturaleza como enemigo resulta sumamente efectivo para justificar la promoción de una cultura política neoautoritaria funcional a un capitalismo global cada vez más violento.

Un proceso en sí mismo positivo en la historia espontánea de la evolución natural, la constante mutación de los virus, que no son como los microbios, un organismo microscópico animal o vegetal, sino sólo trozos de códigos genéticos en proceso de constante transformación para devenir posiblemente en un ser vivo, ha sido absorbido y exacerbado por el capitalismo del siglo XXI hasta convertirlo en detonante de una crisis epidemiológica que amenaza a la totalidad de la sociedad planetaria.

Global Trends 2025, a World transformed, un informe elaborado por el Consejo Nacional de Inteligencia de la CIA en 2008, ya preveía la «emergencia potencial de una pandemia global» derivable de un patógeno como el coronavirus del SARS, que comenzaría en un país con una alta densidad demográfica, donde exista una interacción cercana entre la sociedad humana y los animales - como sucede en varios Estados del Sudeste Asiático y en China-, que se transmitiría hacia otros países a una velocidad sin precedente, generando contagios sobre un tercio de la población mundial y cientos de millones de muertes (National Intelligence Council, 2008:75). Como puede verse, antes de que concluyera la primera década del nuevo siglo, múltiples de las características distintivas de la actual pandemia estaban vislumbradas por este órgano de la Agencia Central de Inteligencia (CIA, por sus siglas en inglés) que elabora evaluaciones prospectivas para la Casa Blanca. Pero Estados Unidos como hegemón global optó por no tomar medidas.

De hecho, la Agencia de los Estados Unidos para el Desarrollo Internacional (USAID, por sus siglas en inglés) como respuesta a la gripe aviar de 2005, lanzó el programa PREDICT. Entre 2009 y 2019, recolectaron más de 140 mil muestras biológicas de varios animales como reservorios potenciales, entre ellos $10 \mathrm{mil}$ murciélagos. Identificaron alrededor de mil 200 virus con potencial pandémico, incluyendo más de 160 coronavirus (Baumgaertner y Rainey, 2020); sin embargo, USAID se remitió a catalogar, jamás diseñó política estratégica preventiva.

En 2015, Bill Gates impartió una conferencia en la que trazó un cierto paralelismo entre la guerra nuclear como el «desastre más temido» del siglo XX 
y la emergencia potencial de una pandemia derivada de un virus como el de la influenza en el siglo XXI. Entrecruzando su intervención de apoyo a la geolocalización permanente de ciudadanos y la Organización del Tratado del Atlántico Norte (OTAN, por sus siglas en inglés) con otra posición con que impulsó la conformación de una política de salud global propiamente liberal, puso énfasis en el contraste entre la canalización de enormes presupuestos para la producción de «disuasivos nucleares» y el prácticamente inexistente financiamiento de un sistema de salud mundial diseñado para prevenir e impedir la emergencia de una pandemia predecible. Dirigió la mirada hacia lo inocultable: la Organización Mundial de la Salud (OMS) monitorea las epidemias, pero no propulsa una política de salud global preventiva (Gates, 2015).

El Banco Mundial ya calculaba que una pandemia podría acarrear un impacto de tres mil millones de dólares. La OMS temía este peligro, al menos, desde hace dos décadas.

La mundialización de la epidemia por covid-19 era prevenible porque era previsible, pero el capitalismo admitió indemne la potencialidad de su estallido. Se tenía vislumbrada la probabilidad de una epidemia transmisible por el aire, similar pero superior a la mal denominada "gripe española» de 1918. La mayor epidemia del siglo XX fue generada como resultado de la barbarie de la Primera Guerra Mundial porque surgió en los cuerpos inmunológicamente débiles de los soldados mutilados, heridos y sobredesgastados. No fue de ningún modo casual que el epicentro de esa pandemia se ubicara en la base militar de Fort Riley, en Estados Unidos. Como los periódicos españoles fueron los primeros en informar sobre esta epidemia que se expandía aceleradamente por el orbe, mientras Estados Unidos y el resto de Europa guardaban silencio con el fin de mantener control político sobre las masas sociales de sus ejércitos, el término "gripe española» surgió, lo que resultó extremadamente conveniente para obstruir la comprensión de su epicentro real en Kansas. Fue de tal magnitud el desvío de la mirada hacia el país donde los mass media la volvieron noticia frecuente que, como afirma Alfred W. Crosby (2003), adquirió el carácter de una «pandemia americana olvidada». Rebasando la cantidad de muertes provocadas por la influenza pandémica de 1918 — que, en un solo año, generó el fallecimiento de entre 30 y 100 millones de personas (Barry, 2004; Davies, 2000) - el informe Global Trends 2025 calculó la potencialidad homicida de una pandemia global en cientos de millones.

La pandemia por covid-19 sobrevino agudizando la crisis económica del capitalismo mundial que ya estaba en curso, pero no fue sólo la preponderancia 
de los intereses cortoplacistas convergentes de los capitales privados la que definió la inexistencia de una política de salud global preventiva. Esa preponderancia se impuso dentro de la hegemonía de la tendencia hacia un Estado neoautoritario planetario, que administra la multiplicación de las lesiones y los cercenamientos de la sociedad mundializada con tal de maximizar la acumulación capitalista global.

Dos tendencias, principalmente, han estado en confrontación como respuesta ante la crisis epocal del capitalismo, con el predominio cada vez mayor de una de ellas: una tendencia neoautoritaria y una tendencia propiamente liberal.

Impasible ante la radicalidad de los efectos destructivos, derivados de la mundialización de la pobreza (Arizmendi y Boltvinik, 2007; Chossudovsky, 2002) y la crisis alimentaria global (Arizmendi, 2019; Bartra, 2011), a la tendencia neoautoritaria ya no le basta dejar operar sin restricciones la violencia económico-anónima inherente a la acumulación de capital — que fue, lo que hizo el inapropiadamente denominado capitalismo «neoliberal», mundializando el principio laissez faire, laissez passer - ; ella empuja el despliegue creciente de violencia político-destructiva ejercida o encubierta por los Estados para manejar la agudización de la lucha mundializada de clases. Mientras que, ante la radicalidad de la crisis epocal, la tendencia propiamente liberal, con la finalidad de que la desestabilización creciente no conduzca a una crisis de gobernabilidad, impulsa la intervención efectiva de los Estados como contrapeso frente a los efectos destructivos de la violencia económico-anónima, oponiéndose al despliegue de violencia político-destructiva.

En la vuelta de siglo, ha resultado hegemónica la tendencia neoautoritaria porque el capitalismo mundial ha optado preferentemente por ella como respuesta ante el hecho de que se encuentra atravesando por el peor periodo en la historia de la tendencia descendente de la tasa de ganancia, sobre todo, para los capitalismos del Norte (gráfica 1).

Analizando agudamente la tendencia descendente de la tasa de ganancia internacional en la perspectiva de la larga duración, esto es como tendencia multisecular, para abarcar desde 1869 hasta 2010, Esteban Maito ha demostrado que, ciertamente, la tendencia descendente de la tasa de ganancia opera en el nivel de la economía mundial, pero que sobre todo ha desplegado su caída más pronunciada en los países centrales, rebasando el declive de ella en los países de las periferias. En nítido contraste con la tasa de ganancia mundial, que cayó de 33 a 18 por ciento aproximadamente, para el periodo comprendido entre 1956 y 2010, y la tasa de ganancia de los países periféricos, que bajó de 45 a 23 por ciento, en 
esos mismos años; los capitalismos del Norte han experimentado una caída de cerca de 23 a poco más de 10 por ciento. Si se observa en la óptica de la larga duración es peor: emerge que los capitalismos centrales pasaron de una tasa superior a 40 por ciento, previa a la Larga Depresión de fines del siglo XIX, a una tasa alrededor de 10 por ciento, en el marco de la crisis de sobreacumulación planetaria del siglo XXI. Ellos se ubican ahora por debajo del pico negativo más pronunciado de la Gran Depresión del siglo XX.

\section{GRÁFICA 1}

Tasa de ganancia promedio de países centrales, países periféricos y a escala mundial (1869-2010)

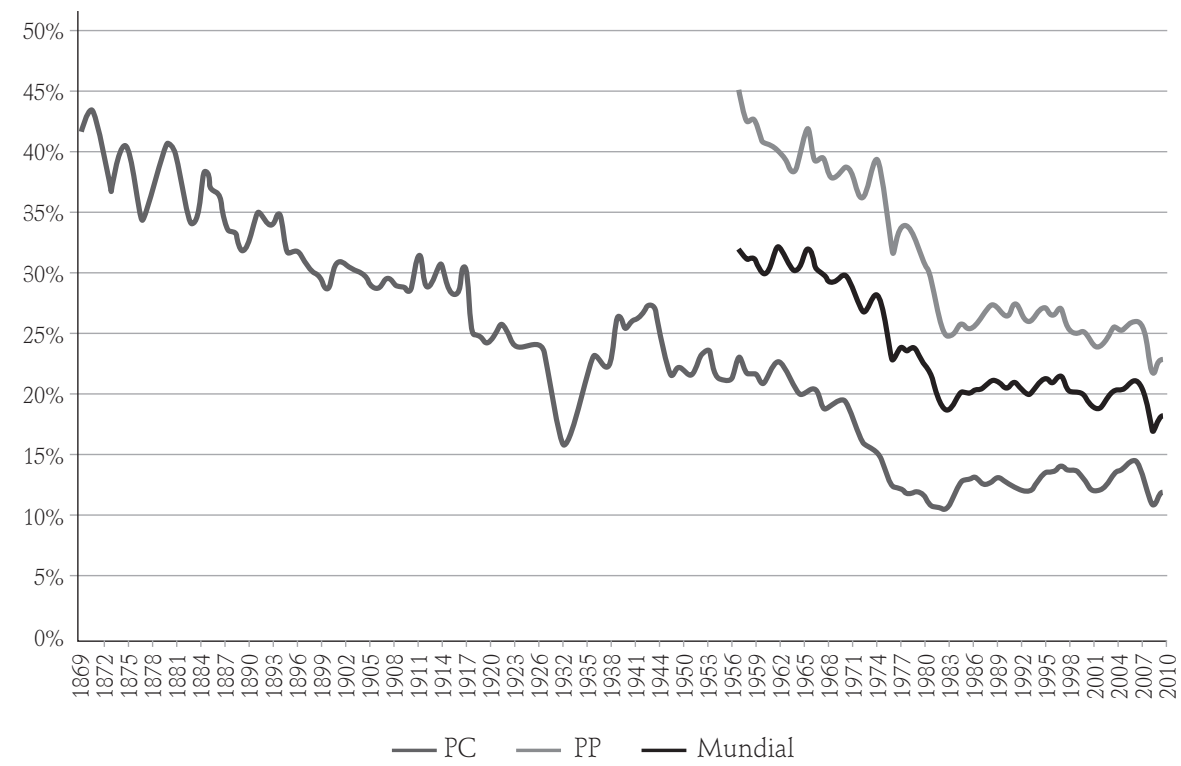

Fuente: Esteban Maito (2013:147)

Esto significa que la respuesta hegemónica del capitalismo mundial ante la emergencia potencial de una pandemia como la de la covid-19 ha sido el planetary management.

No se trata de la deliberada producción de una pandemia, con elevada tasa de reproducción, en el marco de la disputa por la hegemonía mundial. En un principio, el impacto original de esta epidemia sobre China e Irán, suscitó la sospecha de una bioarma empleada por el capitalismo del Pentágono. Ahora, que es constatable que Estados Unidos ha sobrepasado el millón y medio de 
contagios y ha superado los 100 mil fallecimientos, es evidente que la potencia hegemónica en la producción de bioarmas no tiene vacunas ante la crisis por covid-19. De manera complementaria, la insistente presión de Trump por atacar a China atribuyéndole ser responsable de la producción del coronavirus en un laboratorio en Wuhan y hasta su inédita orden de suprimir todo financiamiento a la OMS, cuando Pekín tampoco tiene vacuna, pone al descubierto el profundo interés que tiene la Casa Blanca por atribuir a la producción intencional el surgimiento de la covid-19, a fin de eludir su gravísima responsabilidad en la amplificación de los impactos de la actual crisis epidemiológica en Estados Unidos. Como el Pentágono sabe que las bioarmas jamás se fabrican sin la cura correspondiente, pudo declarar que el coronavirus tuvo un «origen natural».

La pandemia de covid-19 no es resultado del uso geopolítico de una bioarma en la disputa por la hegemonía mundial - lo que no anula que otra epidemia pudiera llegar a serlo, considerando la larga historia del mundo secreto de la guerra biológica no sólo en Estados Unidos, la Unión de Repúblicas Socialistas Soviéticas (URSS), Reino Unido o Alemania, sino también en Irak, Sudáfrica, Japón y Canadá (Barnaby, 2002). Constituye una pandemia previsible ante la cual el poder planetario se mantuvo impasible.

El planetary management conforma la administración tecnocrática neoautoritaria, desde muchos Estados y diversos organismos internacionales (por delante el Fondo Monetario Internacional y el Banco Mundial), de la multiplicación de los contagios y los muertos admisibles en tanto la prioridad inamovible se encuentra cargada hacia la canalización de los máximos recursos para la acumulación capitalista global, no hacia la seguridad vital de la sociedad mundializada. En función de sus jerarquías cortoplacistas, sin generación programada o intencional, el planetary management admitió la potencialidad de una pandemia que, finalmente, se concretó. Externalizó hacia un futuro que ya es nuestro presente, el peligro de una pandemia admitido dentro de la tendencia hacia el estado de excepción planetario. El planetary management ha puesto al descubierto que está dispuesto a manejar así todos los peligros contenidos en la crisis epocal del capitalismo.

La geopolítica de mundialización de las epidemias se puso de manifiesto desde el inicio del nuevo siglo. En 2002-2003, el síndrome respiratorio agudo severo SARSOCoV impactó en 29 países de los cinco continentes, con una tasa de mortalidad aproximadamente de 13 por ciento. La gripe aviar 2004-2006, con la cepa H5N1, comenzó en África, se extendió hacia China, Tailandia y Malasia; después a Europa, afectó a Italia, Grecia, Austria, Alemania, Hungría, Eslovaquia, Eslovenia, 
Francia y España; y, por último, en América Latina, impactó en República Dominicana, México, Bahamas, Colombia y Brasil. La influenza AH1N1, en los años 2009-2010, que comenzó en Veracruz, México, fue un duro anuncio de lo que después concretó la pandemia por covid-19 en 2020. Pero antes llegó la epidemia causada por el coronavirus de síndrome respiratorio de Oriente Medio (MERS), que concentró 80 por ciento de los contagios en Arabia Saudita y se propagó por 27 países. El siglo XXI fue atravesando, sin aprender, por la explosión una tras otra de epidemias de un alcance internacional cada vez mayor hasta llegar a una epidemia totalmente mundializada en 2019-2020.

Desde fines del siglo pasado, se consolidó la mutación histórica de la economía alimentaria mundial que ha disparado la crisis epidemiológica del capitalismo del siglo XXI.

Con base en la americanización de la modernidad (Echeverría, 2008), se mundializó el antiecológico patrón alimentario del capitalismo estadounidense y uno de sus ejes, la producción y el consumo de comida animal. Del lado de la producción subsumida realmente a la mundialización del patrón alimentario del capitalismo americano, un conjunto delimitado de corporaciones transnacionales monopolizan, desde el agribusiness, las ganancias extraordinarias que han derivado de la metamorfosis de la economía alimentaria en uno de los mayores circuitos de la acumulación global, desplazando y desmontando la anterior soberanía alimentaria tan distintiva de un amplio porcentaje de Estados del Sur a lo largo del siglo pasado. Del lado del consumo integrado a la mundialización del patrón alimentario del capitalismo americano, la metamorfosis de tiempo de trabajo doméstico en tiempo de trabajo capitalista ha posicionado como uno de sus soportes materiales decisivos el reemplazo de la producción de alimentos basados en cereales integrales, como era costumbre o propio de la dimensión histórico-moral en el patrón alimentario precapitalista premoderno, por la preparación de alimentos de origen animal, que requieren de un tiempo significativamente mucho menor. La articulación entre estas dos dimensiones la expresa el hecho de que 60 por ciento de la producción mundial de cereales se canaliza como alimento para animales, que luego son convertidos en alimento para sociedades humanas en el mercado mundial —articulación que, pese a la pobreza que propicia para múltiples conglomerados de campesinos en el siglo XXI (Arizmendi, 2020), opera por el desarrollo capitalista de los denominados "países emergentes», principalmente de China.

Ya, desde 2006, en El monstruo llama a nuestra puerta, Mike Davis había dirigido la mirada crítica hacia las megagranjas capitalistas de producción de 
comida porcina como enormes fábricas de generación a gran escala y sumamente acelerada de virus y sus mutaciones. La virología como disciplina científica sabe perfectamente que el agente — el puerco, el pollo u otro animal_-, puede no estar enfermo; sin embargo, de ningún modo eso cancela que en las megagranjas capitalistas las grandes concentraciones de animales producen un intercambio viral de enormes dimensiones. La contigüidad de exorbitantes cantidades de animales - además alimentados con productos genéticamente modificados y a los que se les proporcionan tal exceso de antibióticos que producen la resistencia creciente a ellos de múltiples bacterias-, activa un dinámico intercambio de genes de diversos tipos de gripe (aviar, porcina y humana), que propicia el salto de la barrera entre especies hacia el desplazamiento antigénico abriendo los riesgos potenciales, en cualquier momento, de una epidemia zoonótica mundializable. Big farms make flu, un libro escrito por el biólogo crítico Rob Wallace (2016), prologado por Mike Davis, que recurre a los aportes innovadores de la epidemiología agrícola, demuestra agudamente que las epidemias modernas de ningún modo constituyen un fenómeno natural e indaga las trayectorias de sus patógenos para explicar su surgimiento desde el agribusiness letal dominado por las corporaciones multinacionales.

Precisamente, porque cruzamos por el peor periodo histórico de la tendencia descendente de la tasa de ganancia para el capitalismo central, el poder corporativo planetario se ha convertido en una de sus causas contrarrestantes. Lo es para los capitales corporativos globales que, al dominar la producción y circulación de valores de uso que se han vuelto centrales para la reproducción de la sociedad mundializada, conforman enormes oligopolios que tejen grandes circuitos entrecruzados horizontal, vertical y transversalmente, atravesando múltiples ramas y todos los sectores de la economía planetaria.

ETC Group (2019) ha documentado, de modo pormenorizado, el poder corporativo en la economía alimentaria global. En 2018, las seis empresas mayores dominaron 58 por ciento del mercado mundial de semillas comerciales y transgénicos: Bayer (que absorbió a Monsanto) de Alemania, Corteva Agriscience de Estados Unidos, ChemChina/Syngenta, Vilmorin y Cie/Limagrain de Francia, KWS de Alemania y DLF de Dinamarca. En el complejo cárnico industrial, las aves de corral son la mayor fuente de proteína animal. Para 2025, podrían abarcar 45 por ciento del mercado mundial de comida animal. Dos corporaciones globales, EW Group y Tyson Foods suministran más de 91 por ciento del ganado reproductor comercial para pollos de engorda (es decir, pollos criados para carne). 
Dos compañías, EW Group y Hendrix, controlan la genética de gallinas ponedoras (es decir, gallinas criadas para producir huevos) en todo el mundo. Tres corporaciones controlan casi la mitad (47 por ciento) del mercado de genética porcina comercial: Genus plc, Topigs Norsvin y Hendrix Genetics. Las firmas para gestión de activos, que penetran una gran cantidad de empresas y controlan acciones a lo largo y lo ancho de la economía alimentaria global (en la producción de tecnología para el agribusiness, semillas, ganado avícola, porcino y vacuno, agroquímicos, fertilizantes sintéticos, farmacéuticos para animales y comercio minorista de comestibles), han alcanzado un poder económico excepcional: 18 billones de dólares. Todas esas firmas son estadounidenses: BlackRock, Vanguard Group, State Street Corporation, Fidelity y Capital Group. Si bien, Walmart, es el máximo poder corporativo global en el mercado mundial de alimentos y bebidas, y sigue siendo controlada por sus dueños fundadores, las megafirmas de gestión de activos ya coptaron más de 30 por ciento de acciones de la compañía. Amazon dejó atrás, en el siglo XX, su lema como «la librería más grande de la Tierra», gracias al poder económico que le ha otorgado el comercio en línea global. A lo largo de la próxima década, competirá con Walmart por la hegemonía en el comercio electrónico de comestibles. Facebook, Amazon, Alibaba, Microsoft, Google y Apple, las grandes corporaciones de la red de información y comunicación global, la Big Data, están invadiendo cada vez más ramas del agribusiness planetario, la Big Ag. Tres de los ejes del poder corporativo mundializado — la Big Data, la Big Ag y la Big Pharma_, sin duda, van a salir fortalecidos por la crisis de covid-19.

El mayor dilema reside, justo y ante todo, en que, además de embestir e impedir la soberanía alimentaria de los Estados del Sur, la economía alimentaria mundial específicamente capitalista entabla e impone una relación radicalmente antiecológica con la naturaleza global, destruye el hábitat original del mundo animaly, por ende, rompe las fronteras entre el mundo humano y el mundo viral. Abre la emergencia acelerada de epidemias zoonóticas que no sólo se suceden, sino que se yuxtaponen. Ahora mismo, mientras el mundo dirige la atención a la pandemia por coronavirus, Latinoamérica está atravesando por la peor epidemia de dengue en su historia.

En el marco de la crisis epidemiológica del capitalismo, en todo caso, la versión china de americanización de la modernidad le imprimió su marca a la interiorización del patrón alimentario específicamente capitalista: agregó el consumo antiecológico de comida animal exótica. Con procesos productivos que enjaulan 
en el mismo espacio las más diversas especies animales, que luego son destrozadas con los mismos instrumentos sin las más mínimas medidas de protección ante procesos de mutación viral evidentes. Si el coronavirus se originó o no poco antes, no cabe duda de que fue en China. Todo apunta a que el murciélago es el animal en que surgió y realizó su salto directamente a seres humanos o por mediación del pangolín. La modernidad china agregó su contribución antiecológica a la mundialización de la modernidad americana desde una de sus ciudades más imponentes: Wuhan.

Es de tal magnitud el riesgo potencial de una agudización futura de esta pandemia en China, país que cuenta con un sexto de la población mundial aproximadamente, que, para el periodo 2020-2025, Wuhan ya ha prohibido legalmente la caza, el transporte, la comercialización y el consumo de comida animal salvaje. Sin embargo, sigue sin cuestionarse la radical estructura antiecológica de la economía alimentaria mundial específicamente capitalista.

Aunque la OMS ha promovido una política de salud global liberal que busca romper la cadena de contagio por covid-19, lo que exige asumir una importante caída del PIB en el orbe, también ha respondido a los intereses que definen al planetary management. Guardó y sigue guardando silencio sobre la plataforma histórica antiecológica que ha detonado la geopolítica de las epidemias en el siglo XXI y que, por supuesto, identifica. Ha cubierto los intereses de las corporaciones transnacionales, ante todo americanas, que dominan hegemónicamente la economía mundial alimentaria. No era por filantropía que Estados Unidos financiaba la OMS con 450 millones de dólares cada año, por más que Trump se queja de que representa un financiamiento 11 veces superior al de China. Asimismo, la OMS ha protegido los enormes intereses de la industria farmacéutica transnacional como uno de los mayores negocios de la acumulación capitalista mundial. Una industria global que no tiene reparo en sus prácticas iatrogénicas, combinando curar y enfermar para garantizar la integración interminable de los enfermos como consumidores bioquímicamente dependientes de los fármacos modernos (McTaggart, 2005).

En tanto es la concreción de una época, el cuerpo humano es historia. Atravesamos el tiempo de la crisis epocal en la dominación real o el señorío del capitalismo sobre la naturaleza global.

La pandemia por covid-19 ha puesto al descubierto la crisis epidemiológica del capitalismo como segundo eje de la crisis ambiental mundializada del siglo XXI, al lado del sobrecalentamiento planetario. 
Su impacto va a agudizar la crisis cíclica de sobreacumulación global, propiciando una reducción del PIB de las economías avanzadas en - 6.1 por ciento como promedio general y para Estados Unidos en -5.9 por ciento, en 2020; salvándose China de la recesión, pese a una caída de -4.8 por ciento, por un crecimiento esperado en 1.2 por ciento, según los ajustes en un periodo extremadamente corto, de enero a abril, ofrecidos por el Informe de Perspectivas de la Economía Mundial del FMI (2020a), el cual ha caracterizado el impacto del "gran confinamiento» en la economía mundial como «la peor desaceleración desde la Gran Depresión» (FMI, 2020b).

La Cepal (2020) pronostica un aumento de la pobreza extrema, la pobreza y la desigualdad en América Latina, con mayor vulnerabilidad para los adultos mayores, los hijos de las familias pobres presionados para integrarse al trabajo infantil y los pueblos originarios o indígenas; a la par que el Programa Mundial de Alimentos (PMA) de la Organización de las Naciones Unidas (ONU) ha puesto énfasis en la probabilidad de "hambrunas de proporciones bíblicas», si se interrumpen la producción o la circulación internacional de víveres que proporciona para 30 millones de personas, que dependen exclusivamente de su asistencia para abrirse acceso a alimentos cada semana.

Si ya, debido a la dominación monopólica de las corporaciones transnacionales (Rubio, 2014) y su subordinación de la circulación de alimentos a la maximización de las ganancias extraordinarias, atravesamos por la peor crisis alimentaria en la historia de la humanidad, justo cuando existen las fuerzas productivas para generar el doble de los alimentos requeridos por la totalidad de la sociedad planetaria, y, peor aún, cuando sobre el siglo XXI pende la amenaza inédita de la transición potencial del estado actual de escasez espuria o artificial de alimentos hacia un estado futuro de su escasez absoluta, conforme aumenten los impactos del sobrecalentamiento en los cultivos del orbe (Arizmendi, 2019; IPCC, 2014). La pandemia por covid-19 ha vuelto complejos los peligros de la crisis alimentaria en el corto plazo, puesto que ha abierto la probabilidad de hambrunas motivadas por cuarentenas, desempleo o contagios.

Sin duda, la crisis epidemiológica del capitalismo recrudece los efectos históricos en curso de todas las dimensiones constitutivas de la crisis epocal del capitalismo. Es una crisis que resulta redondamente consistente, con este peculiar estatus histórico, justo porque incluye pero a la vez desborda la mayor crisis cíclica de sobreacumulación en la historia del capitalismo - la primera propiamente planetaria-, desde el origen y el trend secular de la crisis ambiental mundializada, que la lleva a configurarse en sí misma como una era (Arizmendi, 2016). 
Mientras el sobrecalentamiento planetario como primer eje de la crisis ambiental mundializada se dirige hacia la devastación de la naturaleza exterior $y$, desde ahí, pone en peligro la reproducción vital de la humanidad; la crisis epidemiológica del capitalismo impacta directamente en la naturaleza interior, es decir, en la materialidad corporal de los seres humanos. La crisis epidemiológica planetaria como concreción de los límites históricos a que está arribando el señorío o la dominación real del capitalismo sobre la naturaleza está constituida por todas las epidemias derivadas de la interacción antiecológica de la economía alimentaria, específicamente capitalista con el mundo animal y su mundo viral, aunque también debe incluirse dentro de ella la tendencia secular al acrecentamiento de enfermedades infecciosas (como el cólera, el dengue, el paludismo y la hepatitis) que resultará del impacto del sobrecalentamiento planetario. Para 2030, según prevé el Grupo Intergubernamental de Expertos sobre el Cambio Climático (IPCC, por su acrónimo en inglés) de la ONU, el clima podrá haberse desplazado más de 240 kilómetros hacia el norte, hecho que afectará con enfermedades infecciosas que jamás ha padecido Europa.

Stricto sensu, la pandemia por covid-19 es la expresión implacable pero particular de una crisis epidemiológica planetaria de orden mayor, que se ha puesto al descubierto para cambiarlo todo, y que pone en evidencia sus mayores peligros desde su interacción con las demás dimensiones constitutivas de la crisis epocal del capitalismo. Si bien la dinámica natural de las mutaciones virales es en sí misma sumamente inestable y, por tanto, impredecible, cabe afirmar que, en tanto producto histórico del señorío del capitalismo sobre la naturaleza, la crisis epidemiológica global se encuentra inserta en el trend secular de agudización creciente de la crisis ambiental mundializada. Para asumir el profundo desafío que tiene nuestra era ante sí, es mejor no hacerse ilusiones: de ningún modo, ésta constituye una crisis transitoria o pasajera. Desde la persistencia de la americanización de la modernidad y la economía mundial alimentaria específicamente capitalista y, más aún, con su entrecruzamiento con la marcha creciente del sobrecalentamiento planetario, su tendencia, de modo inminente, apunta al peligro de hacer de la pandemia por covid-19 sólo la primera de la multiplicación de otras epidemias mundializables que traerá el futuro de este siglo. 


\section{Tendencia a Estado neoautoritario planetario y crisis de la migración forzada internacional}

La caracterización de la covid-19 como una pandemia global generada por lo que ha dado en llamarse un "virus democrático» es pura ilusión. La imagen del viceministro de Salud de Irán, Iraj Harirchi, de que «este virus no distingue entre ricos y pobres o entre estadista y ciudadano común", si bien llama la atención que también miembros de la clase dominante y la clase política están en riesgo, no obstante, propicia la invisibilización de que, ante todo, son la pluspoblación sobrante moderna y el ejército de reserva que integra las filas de la migración forzada internacional quienes están en elevado peligro. El coronavirus de ningún modo es un "virus democrático", ha sido un virus detonante de una pandemia, ante todo, aprovechada por la tendencia a la propulsión de estado de excepción planetario. Principalmente, es el cuerpo de la pluspoblación global sobrante el que está bajo amenaza.

Tres han sido las configuraciones históricas que ha adquirido la tendencia a estado de excepción tanto en el Sur global como en el Norte global, tanto en Occidente como en Oriente, como respuesta hegemónica o preponderante del capitalismo ante la pandemia del coronavirus.

Una primera configuración de la tendencia neoautoritaria, en los Estados del Sur, se dio en aquellos países en los cuales se constituyeron, propiamente, estados de excepción y toques de queda. En América Latina, Colombia, Ecuador, Bolivia y Chile por delante. Estados de excepción específicamente constituyen configuraciones extremas en la modernidad capitalista en los que, como ha enfatizado Giorgio Agamben (2006), en Homo Sacer, se decreta un derecho violatorio de todo derecho. Es así porque en ellos se articula la violencia económico-anónima inherente de modo permanente o estructural a la acumulación capitalista con el ejercicio de una violencia de otro orden, propulsada o encubierta por la clase política, que se dirige a la proscripción de libertades y hasta a la legalización del derecho de matar: la violencia político-destructiva. A partir de propagar una especie de quid pro quo histórico, múltiples Estados han convertido las políticas de salud, imprescindibles para el rompimiento de la cadena de contagio para enfrentar la crisis epidemiológica por covid-19, en un vehículo de políticas de gobernabilidad neoautoritaria sobre la lucha de clases imponiendo estados de excepción. Las politicas de cuarentena o resguardo social, de ningún modo, son sinónimo de políticas neoautoritarias de excepcionalidad. La ruptura de la cadena de contagio puede impulsarse desde la democracia 
participativa, convocando a la sociedad civil a la asunción de la cuarentena o el confinamiento voluntariamente, sin proscripción de libertades - claramente fue el caso de México. Los Estados latinoamericanos que impusieron políticas de excepcionalidad instalaron la desarticulación represiva de movimientos de protesta social y han agudizado, mediante la deuda externa con el FMI, la acumulación por desposesión sobre sus naciones.

Una segunda configuración de la tendencia neoautoritaria se concretó en aquellos Estados con políticas de tenovigilancia total basadas en innovaciones del siglo XXI. Bajo el pretexto de identificación de ciudadanos contagiados o que tuvieron contacto con enfermos y muertos por coronavirus para definir cuarentenas selectivas rápidamente, por un lado, China y Corea del Sur recurrieron a la geolocalización permanente de sus ciudadanos desde celulares y con bases de datos centralizados, por otro, Singapur y Australia emplearon tecnologías Bluetooth desde los teléfonos celulares para que alguien con covid-19 emitiera un código identificatorio a otros usuarios en un radio de dos metros a la redonda $y$, a la par, mensajes a todos aquellos con quienes tuvo contacto para romper la cadena de contagios. El proyecto de dominación total del Gran Hermano de Orwell se ha quedado corto. La invasión de la vida íntima, el registro de las actividades cotidianas, la identificación del círculo social y las alianzas políticas, el levantamiento del bioexpediente de cada quien, el seguimiento de ciudadanos con drones, todo esto y mucho más se volvió factible a partir de esta nueva modalidad de vigilancia omnímoda. Ramonet la ha llamado coronóptikon. Tecnovigilancia total innovadora inserta en la tendencia a estado de excepción que introduce y consigue su aceptación social bajo la justificación de la lucha contra un «enemigo invisible».

En el caso de China, el capitalismo autocrático-estatal - una configuración del capitalismo sin el Estado como única personificación del capital (en contraste con la URSS), con fuerte desarrollo de corporaciones privadas y un sistema político unipartidista-, ha recurrido a políticas de tecnovigilancia total de modo intermitente cambiando su aplicación entre provincias desde 2010. El manejo literalmente draconiano de las políticas de tecnovigilancia total y el disciplinamiento social ante las cuarentenas sienta un grave precedente para el desarrollo neoautoritario del capitalismo autocrático-estatal.

Una tercera configuración de la tendencia neoautoritaria se concretó en los Estados que ejercieron una política neodarwinista, en capitalismos tanto del Norte como del Sur. Por delante Estados Unidos, Reino Unido y Brasil. Bajo la ilusión 
de la denominada "política de rebaño", cínicamente, plantearon que había que admitir y administrar la multiplicación de los enfermos y los muertos como presunta mediación ineludible para lograr una respuesta inmunológica capaz de generar anticuerpos contra el coronavirus en la sociedad. Sálvese quien pueda, en ese marco, no significaba sólo sálvese quien pueda desarrollar anticuerpos, significa sálvese quien tenga los recursos económicos para comprar servicios médicos mercantificados capitalistamente. La configuración de Estado neodarwinista la concretaron Trump, Johnson y Bolsonaro, agudizando gravemente los impactos dolorosos de la crisis por covid-19 en sus países. No es casual que, a excepción de Rusia y España, ellos sean los que ocupan los primeros lugares de contagios en la actual crisis epidemiológica global.

Hoy ya se sabe que es muy bajo el porcentaje de enfermos de covid-19 que producen anticuerpos: 2 o 3 por ciento. Esto significa que haría falta mínimo una década, muy posiblemente más, para llegar a 70 por ciento de la sociedad con anticuerpos contra el coronavirus.

El Imperial College London realizó un estudio matemático con el que concluyó que si el Reino Unido continuaba con la política de «inmunidad del rebaño», fallecerían más de un cuarto de millón de ciudadanos; y que en Estados Unidos morirían entre un millón y 1.2 millones de personas. Ese fue el estudio que presionó a Johnson para aplicar, tardíamente, la política de supresión o ruptura de contagios planteada por la OMS. Muy probablemente es el mismo estudio que Trump tenía en mente cuando afirmó que si fallecían 100 mil estadounidenses habrían hecho muy buen trabajo. Ahora que Estados Unidos ya rebasó esa cifra, salió a decir que podrían llegar a ser hasta 240 mil muertes por coronavirus en Estados Unidos, a la vez que está presionando sobremanera por la reactivación de la acumulación capitalista y el cierre de las cuarentenas.

La cantidad de muertos en Estados Unidos supera con creces el número de muertes sumadas por las guerras de Irak y Afganistán, el ataque a las torres gemelas y el huracán Katrina. Frida Ghitis — colaboradora de CNN y columnista de The Washington Post - afirma que 25 mil muertes habrían podido evitarse. Los médicos y los biólogos más críticos en Estados Unidos calculan que podría haber sido 90 por ciento de ellas.

Trump personifica radicalmente la tendencia neoautoritaria del capitalismo del siglo XXI. Una tendencia que no tiene ningún reparo en combinar sobreexplotación laboral y administración de la multiplicación de los muertos entre la pluspoblación sobrante en Estados Unidos. 
Con su documento Immigrant workers: vital to the U.S. Covid-19 response, disproportionately vulnerable, elaborado por Julia Gelatt (2020), el Migration Policy Institute (MPI), ha demostrado que los migrantes son trabajadores que participan ampliamente en varias de las funciones laborales clave para mantener a los ciudadanos americanos «sanos, seguros y alimentados».

Trabajadores de origen migrante - es decir, que nacieron fuera de Estados Unidos, independientemente de si tienen ya ciudadanía americana, son residentes legales permanentes, carecen de estatus legal o son trabajadores temporales-, corresponden a 17 por ciento de los 156 millones de civiles que laboraron entre 2014-2018.

En el ámbito de la economía de la salud, conforman 29 por ciento de los médicos, 22 por ciento de los auxiliares de enfermería, 29 por ciento de los cuidadores del hogar y 24 por ciento de los conserjes y limpiadores de edificios en la industria de la salud; asimismo, 38 por ciento de los asistentes de salud en el hogar y 25 por ciento de los asistentes de cuidado personal, que atienden a pacientes ancianos y discapacitados en sus hogares, además son 23 por ciento de los farmacéuticos minoristas. Todos ponen en riesgo su propia salud para asumir sus funciones laborales en medio de la pandemia.

En el ámbito de la economía alimentaria, cumplen una función esencial en la cadena de aprovisionamiento de alimentos en Estados Unidos. Al menos, representan 22 por ciento de los trabajadores en la economía alimentaria, excluyendo restaurantes. Los inmigrantes son 30 por ciento de los trabajadores agrícolas, 27 por ciento de los trabajadores en la producción industrial de alimentos, 17 por ciento de los trabajadores en su transporte, 23 por ciento de la fuerza de trabajo en el comercio al mayoreo y 17 por ciento en el comercio al menudeo (MPI, 2020). Paralelamente, son 26 por ciento de los trabajadores que producen suministros de jabón y de limpieza. En cuyas industrias, conforman 50 por ciento de los empacadores, 42 por ciento de los operadores de máquinas de empaque, 39 por ciento de los trabajadores de procesamiento y 38 por ciento de los panaderos.

Como se aprecia, la fuerza de trabajo de origen migrante no tiene nada que demostrar respecto de su amplio y relevante papel en Estados Unidos ante la pandemia contemporánea. Sin olvidar que también cuenta con participación en la investigación calificada que se encuentra produciendo la invención de una vacuna contra el coronavirus.

Sin embargo, los migrantes no sólo están en primera fila de la respuesta a la pandemia, también la están en la de quienes reciben sus agudos impactos. 
Según el MPI, en Estados Unidos, son al menos 12 millones de personas. Constituyen un conjunto social de alta vulnerabilidad, dado que también participan en múltiples de las ramas económicas y funciones laborales que, bajo el impacto de la pandemia actual, están siendo objeto de drástica reducción de la fuerza de trabajo por el capitalismo estadounidense.

En 2018, conformaban 59 por ciento de las empleadas domésticas, 38 por ciento de los chefs, 30 por ciento de los cocineros, 22 por ciento de los trabajadores de preparación de alimentos, 78 por ciento de los manicuristas y pedicuristas, 63 por ciento de las mucamas, 52 por ciento de la fuerza laboral en los servicios de lavandería y tintorería, y 46 por ciento de los asistentes de estacionamiento, 41 por ciento de los conserjes y 2 por ciento de los trabajadores de mantenimiento y reparación.

La crisis por covid-19 los está impactando duramente. De por sí ya 38 por ciento de los migrantes vivía en hogares de bajos ingresos (inferiores a 200 por ciento de la línea de pobreza federal), con familias más grandes que sus pares nacidos en Estados Unidos - como expresión de una estrategia de sobrevivencia obligada a multiplicar sus miembros para abrirse acceso a más recursos- y, al menos, un hijo menor en casa; 28 por ciento carece totalmente de cobertura de seguro de salud, que es el doble de la tasa de trabajadores similares nacidos en Estados Unidos.

El capitalismo estadounidense entabla una relación de tres órdenes con la fuerza de trabajo de origen migrante: 1. La subsume y explota integrándola a las masas de trabajadores en activo del mercado laboral formal — como masas que se componen de trabajadores con y sin ciudadanía estadounidense. 2. La subsume y sobreexplota integrándola a las filas del estrato o capa flotante del ejército de reserva, que entran y salen del mercado laboral tanto formal como informal, tanto legal como ilegal. 3. La lanza a las filas del ejército internacional de reserva enteramente cercenables, es decir, condenables a muerte por despliegue de la violencia económico-anónima capitalista o por el ejercicio neoautoritario de su violencia político-destructiva.

En el marco de la crisis por covid-19, el capitalismo estadounidense se ha manejado sometiendo la migración forzada internacional a un vaivén entre el segundo y el tercero de estos órdenes. En Nueva York, para que los ciudadanos estadounidenses pudieran asumir la cuarentena, el capitalismo americano asignó, sobre todo, a la fuerza de trabajo migrante las funciones de traslado de alimentos y valores de uso de los restaurantes y los comercios a los hogares. 
Con derechos de ciudadanía negados y sin cobertura de seguro de salud, afectados por la pobreza, con condiciones laborales degradadas y sin contar con las medidas de protección adecuadas, la fuerza de trabajo migrante se puso en riesgo. No es una contingencia que, aproximadamente, un tercio de los muertos en Nueva York provengan de las filas de la pluspoblación sobrante migrante de origen hispano.

Otro tercio proviene de afroamericanos que, justo porque están siendo objeto de una política neoautoritaria dispuesta a sacrificarlos en el marco de la crisis por covid-19, explotaron contra la política de estado de excepción de la modernidad americana, a partir del asesinato de Floyd, que sólo constituye «una parte» reveladora aunque «menor» de un «crimen» de muchas mayores dimensiones, como bien apuntó Chomsky (2020).

La Casa Blanca ha recurrido a la pandemia no sólo como un medio para justificar recrudecer su política neoautoritaria contra la migración forzada internacional, la ha empleado como un medio funcional a la propagación de la muerte.

Con la construcción de 40 centros de detención, para elevar su cifra total en Estados Unidos a 220, Trump edificó, literalmente, una maquinaria neoautoritaria de cacería antiinmigrantes, con rienda suelta para el amplio despliegue de violencia político-destructiva y violación prácticamente irrestricta de derechos humanos. Convertidos en un canal de acumulación para el capital privado, dirigido a obtener ganancias extraordinarias millonarias, su finalidad de elevar de 33 mil a 60 mil las detenciones diarias de 2016 para 2021, estaba asumida y desbordada si se suman las detenciones en los puestos de control fronterizos entre Estados Unidos y México que llegaron a ser de 80 mil a principios de 2020.

Si 2019, alcanzó la mayor deportación de mexicanos en la era Trump, 205 mil; 2020 agregó la detención y deportación masiva de migrantes de diversas nacionalidades violando los más mínimos protocolos internacionales de derechos humanos sin protegerlos de una epidemia mayor como la de covid-19. Para decirlo mejor, la tendencia neoautoritaria estrenó hacer de la propagación de la pandemia entre migrantes ilegales un medio para la multiplicación deliberada de los contagios y los muertos con el fin politico de amenazar y sacrificar pluspoblación sobrante internacional.

Si bien Estados Unidos ha llevado al extremo la política de excepcionalidad, la tendencia del capitalismo neoautoritario en el siglo XXI ya venía propulsando la militarización y la violación de derechos humanos como la regla para el manejo de la migración internacional forzosa. 
Como producto de la derrota de la anterior soberanía nacional ejercida en el siglo pasado por los Estados del Sur, la mundialización de la pobreza, la crisis alimentaria global, la violencia criminal del capitalismo necropolítico y las guerras, en el nuevo siglo, la migración a escala mundial ha estado en aumento.

Según el Informe sobre las Migraciones en el Mundo 2018 de la ONU, el número de migrantes internacionales alcanzó la cifra récord de 258 millones, en 2017, lo que representa un incremento de 49 por ciento respecto del año 2000, cuando correspondía aproximadamente a 173 millones. Si se le contrasta con el periodo previo al «neoliberalismo», emerge que representa un aumento de 303 por ciento respecto del año 1970, cuando su magnitud alcanzaba los 85 millones.

En este marco, la migración forzosa internacional ha adquirido una dimensión sin precedente. Según el Alto Comisionado de las Naciones Unidas para los Refugiados (ACNUR), para fines de 2015, ya existían 65.3 millones de personas desplazadas forzosamente. Casi 6 millones más que el año anterior.

La crisis epocal del capitalismo del siglo XXI contiene como una de sus dimensiones esenciales la mayor crisis de migración forzosa en la historia de la mundialización.

Estados Unidos es el destino al que mayor cantidad de migrantes buscan arribar: aproximadamente 20 por ciento de la migración global. México se ha convertido en epicentro geopolítico de la alteración de las rutas de migración forzada regulares Sur/Norte. El exorbitante aumento de la migración forzada, proveniente no sólo de Centroamérica, sino también de Asia y hasta África, pone al descubierto un proceso trágico crucial: la derrota del monopolio defensivo de los Estados del Sur sobre sus recursos naturales excepcionalmente ricos y la imposición de una sobreexplotación brutal sobre su fuerza de trabajo, que ya era extremadamente barata pero así es puesta en condiciones de peligro.

La respuesta de Estados Unidos, que pone por delante violencia político-destructiva como arma para administración represiva de la migración forzada, no se mide en referencia al porcentaje que significan los migrantes respecto de la población estadounidense, tampoco en referencia al costo de una infraestructura para brindarles asilo - lo que una reconfiguración liberal del sistema de Estado perfectamente podría llevar a cabo. Más bien, se mide por la tendencia al cambio en la rapport de forces demográfica al interior de Estados Unidos para mediados del siglo XXI. Aunque el capitalismo estadounidense requiere, de modo oscilante pero innegable a la vez, de ejército de reserva internacional, los crecientes flujos de la migración forzosa han alcanzado una magnitud que ya le son contraproducentes. 
La ofensiva de la ultraderecha contra la migración forzada internacional, de ningún modo es reductible a mera retórica o a simulación política. Existe una compleja e inestable combinación de funcionalidad y antifuncionalidad de la pluspoblación sobrante global para los capitalismos del Norte.

Si bien la tasa de crecimiento demográfico está disminuyendo para el conjunto social cuyos ambos padres son migrantes, va en aumento la tasa de los hijos con un padre migrante, mientras la tasa de reproducción de la población originalmente estadounidense está ya por debajo de la renovación de su magnitud actual (gráfica 2).

\section{GRÁFICA 2}

Índice de crecimiento demográfico según identidad de los padres

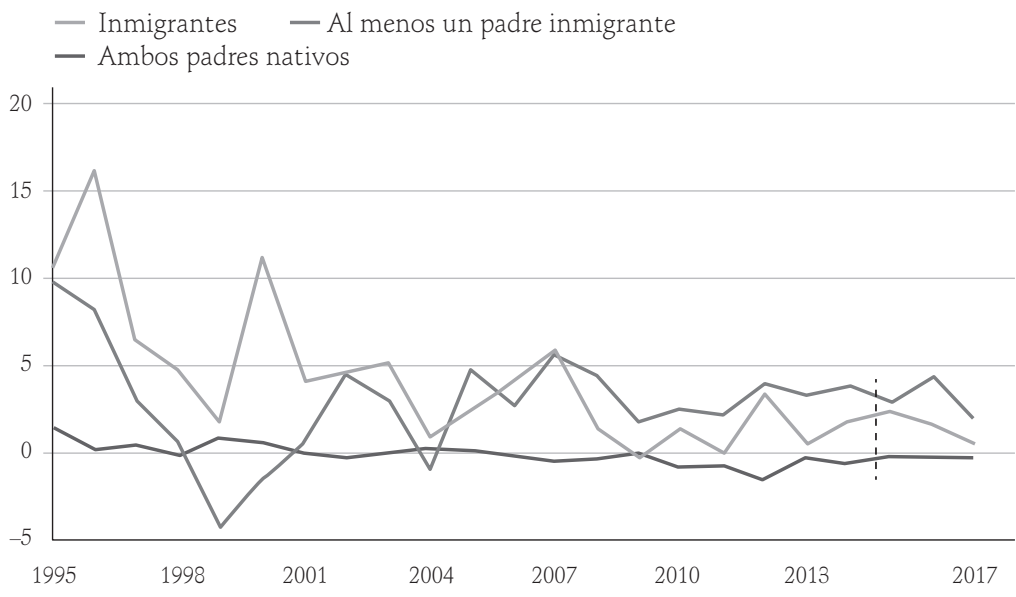

Fuente: Hamilton Project, Current Population Survey.

Se calcula que, de aquí al 2060, la población estadounidense crecerá aproximadamente en 100 millones, para pasar de 326 a 417 millones. Un incremento casi de 30 por ciento de la población, que traerá consigo una profunda recomposición étnica. Los blancos protestantes son cada vez de mayor edad y con menor descendencia. Para 2044, se prevé que más de 50 por ciento de la población en Estados Unidos corresponda a alguna minoría étnica. Para 2060, la población blanca americana descenderá de 62 a sólo 43 por ciento, mientras la población hispana pasará de 18 a casi 29 por ciento. Un margen cada vez más delgado, apenas arriba del 10 por ciento, diferenciará la población de blancos americanos de la población hispana. Como puede observarse, la tendencia hacia la redefinición de la 
correlación de fuerzas demográficas en el capitalismo estadounidense es implacable y, sin duda, la acelera el explosivo crecimiento contemporáneo de la migración forzada internacional.

Mutatis mutandis, es el mismo escenario en el capitalismo europeo. Cada vez más, el Sur está en el Norte. De ahí que, al interior de Estados Unidos y, en general, en los capitalismos centrales, se esté librando una auténtica guerra demográfica como dimensión de la lucha mundializada de clases.

La tendencia a estado de excepción planetario busca revertir con politicas neoautoritarias o neofascistas la modificación en la rapport de forces en los capitalismos del Norte que está agudizando la migración forzada internacional. Es indudable que Chomsky tiene toda la razón cuando afirma que Trump, y más que él, la ultraderecha del siglo XXI, le viene imprimiendo una nueva configuración decadente al lema fascista: iViva la muerte!

\section{Conclusiones}

Slavoj Žižek — con su juego irónico de las palabras pandemia y pánico en su término pan(dem)ic_, y Giorgo Agamben — con su declaración a Quidlibet calificando como medidas frenéticas e irracionales las políticas aplicadas ante una «supuesta epidemia» por coronavirus-, han puesto énfasis radical en la crítica a la tendencia hacia un estado de excepción global; sin embargo, introducen un tipo de plataforma giratoria puesto que desplazan y pasan por alto el fundamento concreto de la crisis global contemporánea: la pandemia por covid-19 constituye una expresión real, particular e implacable, de una crisis mayor, es decir, de la crisis epidemiológica global como dimensión esencial de la crisis epocal del capitalismo del siglo XXI.

La crisis epidemiológica del capitalismo constituye el segundo eje, al lado del sobrecalentamiento planetario, de la crisis ambiental mundializada de nuestro tiempo. Mientras el trend secular del sobrecalentamiento planetario apunta a la devastación de la naturaleza exterior, la crisis epidemiológica del siglo XXI apunta a la devastación de la naturaleza interior, es decir, de los cuerpos de los seres humanos.

La tendencia a estado de excepción planetario de ningún modo es sinónimo de inexistencia de la crisis epidemiológica del siglo XXI, exactamente al revés, constituye la respuesta neoautoritaria a ella. 
El siglo XXI tiene ante sí dos encrucijadas yuxtapuestas para la definición de su porvenir.

En una encrucijada jalonean la tendencia a estado de excepción planetario y la tendencia hacia un liberalismo del nuevo siglo - que no puede remitirse a duplicar el Estado liberal del siglo XX, puesto que enfrenta la crisis ambiental mundializada, la crisis alimentaria global y la crisis epidemiológica del capitalismo.

La trayectoria hegemónica por la que optó el capitalismo ante la pandemia por covid-19 ha consistido en el apuntalamiento del estado de excepción planetario. Tanto en el Norte global como en el Sur global, tanto en Occidente como en Oriente, hemos visto el avance de lo que Shoshana Zubbof (2019) denomina The Age of Surveillance Capitalism - la era del «capitalismo de la vigilancia». En el mismo capitalismo americano, dos corporaciones enfrentadas de la Big Data, Google y Apple, se han unido para ofrecer métodos de tecnovigilancia total para el Estado. Ya no se trata sólo de la mercantificación oculta de la información indexada en la web para proporcionar a las corporaciones globales la ampliación de sus poderes oligopólicos en los mercados a partir de identificar las preferencias de los usuarios; incluso no nada más está en juego la identificación secreta y anticonstitucional de las posiciones y preferencias políticas de los ciudadanos para diseño de tácticas diversas pero complementarias como teatro adaptadas a cada grupo social específico para su engaño y manipulación estratégica; se trata de la invasión total de la identidad biopsicológica — con expedientes genéticos y médicos-, la socialidad y la vida cotidiana de todos y cada uno de los sujetos del mundo, con métodos de tecnovigilancia y geolocalización permanente articulados on line desde la inteligencia artificial, en acuerdo a los cuales se pretende que los comportamientos individuales y sociales puedan ser estimulados, favorecidos, obstruidos, reprimidos o destruidos según sean funcionales o no a la tendencia a estado de excepción planetario. Independientemente de que la soberanía política siempre estará ahí como un potencial de afirmación de la libertad humana ejercible en cualquier momento, no cabe duda de que lo que Zubbof califica como «la era del capitalismo de la vigilancia» responde al proyecto histórico de hacer del siglo XXI el tiempo del estado de excepción planetario como respuesta a la agudización de la lucha mundializada de clases que deriva de las múltiples dimensiones constitutivas de la crisis epocal del capitalismo.

Frente y contra esa tendencia neoautoritaria, en el marco de la crisis por covid-19, la tendencia propiamente liberal ha propulsado la intervención del 
sistema de Estados como contrapeso ante los efectos destructivos de la articulación creciente de violencia económico-anónima y violencia político-destructiva en el capitalismo del siglo XXI.

Sin embargo, ir al fondo de la crisis epidemiológica del capitalismo exige abrir camino a la fundación germinal pero creciente de inéditas formas ecologistas y soberanas del proceso de reproducción vital de las naciones del Sur, acompañándolas con reestructuración radical de la economía alimentaria global. Proyectos que el liberalismo del nuevo siglo, no se está planteando. Asimismo, ir a la raíz de la crisis migratoria global exige conformar modalidades alternativas de la reproducción de las nacionalidades del Sur global y propulsar la articulación estratégica de las clases subalternas desde una alianza contrahegemónica Sur-Norte.

En este marco, el siglo XXI, tiene frente a sí una segunda encrucijada histórica de otro orden. Una disyuntiva en la que se enfrentan la tendencia por la reconfiguración del capitalismo, sin ir más allá de él mismo, y la tendencia que pugna por una modernidad alternativa, desde dentro del capitalismo planetario pero contra él, presionando por edificar desde los bordes de nuestro tiempo la mundialización de una modernidad alternativa.

Si bien, al mirar panorámicamente la marcha de la crisis epidemiológica del capitalismo del siglo XXI, podría afirmarse que el futuro prácticamente comenzó hace dos décadas, asimismo, si los dominados modernos optan por identificar y asumir a contrapelo los límites históricos radicales a los que ha arribado el señorío o, lo que es lo mismo, la dominación real del capitalismo planetario sobre la naturaleza global y el proceso de reproducción vital del sistema de naciones, también cabría afirmar que, para emplear la expresión de Boaventura de Souza (2020) en La cruel pedagogía del virus, "el futuro puede comenzar hoy».

\section{Referencias}

Agamben, Giorgio (2006), Homo Sacer, España, Pre-Textos.

Arizmendi, Luis (2020), "Modernidad barroca y pobreza campesina en el siglo XXI», en Julio Boltvinik y Susan A. Mann (coords.), Pobreza y persistencia campesina en el siglo XXI. Teorías, debates, realidades y politicas, México, Siglo XXI.

(2019), «Crisis alimentaria en el marco de la crisis epocal del capitalismo del siglo XXI», en Francis Mestries, iCrisis agroalimentaria mundial o crisis civilizatoria?», México, Universidad Autónoma Metropolitana. 
(2016), «El planetary management de la crisis ambiental mundializada», en Luis Arizmendi, El Capital ante la crisis epocal del capitalismo, Instituto Politécnico Nacional, México.

Arizmendi, Luis y Julio Boltvinik (2007), "Autodeterminación como condición de desarrollo en la era de mundialización de la pobreza», Mundo Siglo XXI (9), pp. 35-43.

Barnaby, Wendy (2002), Fabricantes de epidemias. El mundo secreto de la guerra biológica, México, Siglo XXI.

Barry, John M. (2005), The great influenza, USA, Penguin.

Bartra, Armando (2011), "Hambre, dimensión alimentaria de la gran crisis», Mundo Siglo XXI (26), pp. 11-24.

Baumgaertner, Emily y James Rainey (2 de abril de 2020), «Trump administration ended coronavirus detection program", Los Angeles Times, en https://www.latimes. com/science/story/2020-04-02/coronavirus-trump-pandemic-program-viruses -detection

Cepal (2020), El desafío social en tiempos del covid-19, en https://www.cepal.org/es/ publicaciones/45527-desafio-social-tiempos-covid-19

Chossudovsky, Michel (2002), Globalización de la pobreza y Nuevo Orden Mundial, México, Siglo XXI.

Crosby, Alfred W. (2003), America's forgotten pandemic, Cambridge, Cambridge University Press.

Davies, Pete (2000), The devil's flue, USA, Owl Books.

Davis, Mike (2006), El monstruo llama a nuestra puerta, España, El Viejo Topo.

De Souza, Boaventura (2020), La cruel pedagogía del virus, Argentina, Clacso.

Echeverría, Bolívar (2008), La americanización de la modernidad, México, ERA.

Fondo Monetario Internacional (abril 2020a), Informe de perspectivas de la economía mundial, en https://www.imf.org/es/Publications/WEO/Issues/2020/04/14/weo-april -2020\#Introducción

(2020b), El gran confinamiento. La peor desaceleración económica desde la Gran Depresión, en https://blog-dialogoafondo.imf.org/? $p=13190$

Gates, Bill (2015), iLa próxima epidemia? No estamos listos, en https://www.youtube. $\mathrm{com} /$ watch? $\mathrm{v}=\mathrm{aG} 1 \mathrm{ohL} 002$ to

Gelatt, Julia (2020), Inmigrant workers: vital to the U.S Covid-19 response, disproportionately vulnerable, USA, en https://www.migrationpolicy.org/research/immigrant-workers -us-covid-19-response

Intergovernmental Panel on Climate Change (2014), Cambio climático 2014. Impactos, adaptación y vulnerabilidad, Suiza, ONU. 
Jo Wetter, Kathy, Hope Shand y Grupo ETC (2019), Tecnofusiones comestibles. Mapa del poder corporativo en la cadena alimentaria, Grupo ETC, en https://www.etcgroup. org/sites/www.etcgroup.org/files/files/etc_platetechtonics_nov_spanish-fin. pdf

Maito, Esteban (2013), «La transitoriedad histórica del capital. La tendencia descendente de la tasa de ganancia desde el siglo XIX", Razón y Revolución, 26, pp. 129-159, en https://www.aacademica.org/esteban.maito/14.pdf

McTaggart, Lynne, (2005), Lo que los médicos no nos dicen: los riesgos de la medicina moderna, España, Terapias Verdes/Navona.

Migration Policy Institute (2020), «The essential role of inmigrantes in the U.S. Food Supply Chain», en https://www.migrationpolicy.org/content/essential-role-immigrants -us-food-supply-chain

Organización de las Naciones Unidas (2018), Informe sobre las Migraciones en el Mundo, Suiza, en https://publications.iom.int/system/files/pdf/wmr_2018_sp.pdf

Rubio, Blanca (2014), El dominio del hambre. Crisis de hegemonía y alimentos, México, Juan Pablos Editor.

Wallace, Rob (2016), Big farms make flu, USA, Monthly Review Press.

Yancy, George (5 de junio de 2020), «Noam Chomsky: Trump has adopted a Viva Death!) aproach to presidency», Truthout, en https://truthout.org/articles/noamchomsky-trump-has-adopted-a-viva-death-approach-to-the-presidency/?eType $=$ EmailBlastContent\&eId=1bbd1e05-5185-42f9-8388-9433d07a4517

Zubbof, Shoshana (2019), The Age of Surveillance Capitalism, Reino Unido, Profile Books.

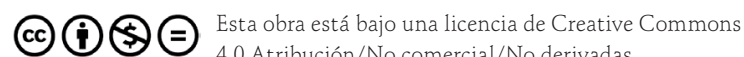
4.0 Atribución/No comercial/No derivadas 